\title{
Violência doméstica: mulheres vítimas da violência e do despreparo das equipes de enfermagem
}

\author{
Domestic violence: women victims of violence and the unpreparedness of nursing teams
}

\author{
Anna Beatriz Brito Domingues" ${ }^{\bullet}$, Erica Cristina da Silva ${ }^{\ominus}$, Helena Ferreira Santos Bispo ${ }^{\bullet}$, Janize \\ Silva Maia ${ }^{\circ}$
}

Universidade Anhembi Morumbi, São Paulo, São Paulo, Brasil. *Autor para correspondência. E-mail: leticiafono3@hotmail.com

\begin{abstract}
Resumo: Introdução: A violência doméstica contra a mulher é compreendida como qualquer ação ou omissão baseada no gênero em algum período de sua vida que lhe cause morte, lesão, sofrimento físico, sexual ou psicológico, além de dano moral ou patrimonial. É um problema de saúde pública de extrema gravidade em função das consequências a curto, médio e longo prazo. Infelizmente, muitos profissionais estão despreparados para realizar o atendimento à vítima, devido a fatores limitantes, resultando na subnotificação dos casos. Objetivo: evidenciar os motivos pelos quais as equipes de enfermagem encontram dificuldade no atendimento a mulheres vítimas de violência doméstica. Revisão: Integrativa de estudos relevantes baseados em evidências, publicados entre 2015 e 2020, nas línguas portuguesa e inglesa, disponíveis na íntegra nas bases de dados SciELO, Science Direct e BVS. Discussão: A integração da literatura selecionada permite inferir que a falta de qualificação para identificar os casos de violência e o conhecimento insuficiente sobre o tema, bem como suas ações mediante essa problemática são as principais evidências do despreparo das equipes de enfermagem para uma assistência adequada à mulher, vítima de violência doméstica. Diante da complexidade que abrange o fenômeno da violência, a assistência de enfermagem demanda planejamento para a promoção de um acolhimento confiável, respeitoso e satisfatório, capaz de oferecer à vítima as opções de enfrentamento. Considerações finais: A conscientização sobre a violência doméstica como um tipo de dano à mulher, bem como os desdobramentos a curto, médio e longo prazo são capazes de beneficiar não só a mulher, mas também todos os membros envolvidos no ambiente intrafamiliar. Sendo assim, é necessário um acolhimento digno, respeitoso e resolutivo a cada mulher, proporcionando assim, uma assistência qualificada e eficaz.
\end{abstract}

Palavras-chave: atenção primária à saúde, cuidados de enfermagem, enfermagem, violência contra a mulher e violência doméstica.

\begin{abstract}
Introduction: Domestic violence against women is understood as any action or omission based on gender at some point in their life that causes death, injury, physical, sexual or psychological suffering, in addition to moral or patrimonial damage. It is an extremely serious public health problem due to the short, medium and long term consequences. Unfortunately, many professionals are unprepared to provide assistance to the victim, due to limiting factors, resulting in underreporting of cases. Objective: to highlight the reasons why nursing teams find it difficult to care for women victims of domestic violence. Review: Integrative of relevant evidence-based studies, published between 2015 and 2020, in Portuguese and English, available in full in the SciELO, Science Direct and BVS databases. DISCUSSION: The integration of the selected literature makes it possible to infer that the lack of qualification to identify cases of violence and insufficient knowledge on the topic, as well as their actions in relation to this issue, are the main evidences of the unpreparedness of nursing teams for an adequate assistance to woman, victim of domestic violence. In view of the complexity that encompasses the phenomenon of violence, nursing care requires planning to promote a reliable, respectful and satisfactory reception, capable of offering the victim the coping options. Final remarks: Awareness about domestic violence as a type of harm to women, as well as short, medium and long term developments are able to benefit not only women, but also all members involved in the intrafamily environment. Therefore, it is necessary to have a dignified, respectful and resolute welcome to each woman, thus providing qualified and effective assistance.
\end{abstract}

Keywords: primary health care, nursing care, nursing, violence against women and domestic violence.

\section{Introdução}

A violência doméstica contra a mulher (VDCM), consiste em qualquer ação ou omissão baseada no gênero em algum período de sua vida, que lhe cause morte, lesão, sofrimento físico, sexual ou psicológico, além de dano moral ou patrimonial. De acordo com a Lei Maria da Penha, acomete qualquer mulher, 
independentemente de sua condição de renda, classe social, raça, etnia, religião, orientação sexual ou idade (Noleto \& Barbosa, 2019).

É um problema de saúde pública de extrema gravidade, por colocar em risco mais da metade da população do país: 103,8 milhões de brasileiras. Em 2013, o Brasil já ocupava o $5^{\circ}$ lugar em um ranking de 83 países onde mais se matam mulheres. São 4,8 homicídios por 100 mil mulheres, sendo que quase $30 \%$ dos crimes ocorrem nos domicílios (Waiselfisz, 2015).

Uma pesquisa do DataSenado (2013) revelou que um em cada cinco brasileiras assumiu ter sido vítima de violência doméstica e familiar provocada por um homem. Os resultados da Fundação Perseu Abramo, com base em um estudo realizado em 2010, também reforçam esses dados: a cada dois minutos, cinco mulheres são violentamente agredidas (Senado Federal, 2013).

Neste triste cenário, emergem algumas questões: “Quando essas mulheres procuram ajuda, a rede está pronta para recebê-las?” “Apesar das políticas públicas e protocolos institucionais existentes para acolhimento e proteção das mulheres vítimas de violência, essas ações funcionam na prática?” O atendimento para casos de violência contra a mulher é complexo por exigir o resgate da autoestima, a autoconfiança e a capacidade de se ver novamente longe do agressor, por isso, fazer uma rede inteira funcionar não é fácil, demanda primeiramente, reconhecimento do poder público. Ainda são muitas as cidades que não estão equipadas de forma adequada para diagnosticar, tratar ou contribuir para a prevenção de novas ocorrências para realizar o enfrentamento à violência de forma efetiva (Baptista et al., 2015).

Infelizmente, mesmo com os índices de violência doméstica aumentando, são muitos os profissionais despreparados para realizar o atendimento à vítima, devido a fatores limitantes, resultando na subnotificação dos casos, cenário este que demanda uma reflexão sobre um acolhimento profissional adequado, respeitoso e humanizado às vítimas. Dessa forma, esse artigo tem como objetivo evidenciar os motivos pelos quais as equipes de enfermagem encontram dificuldade no atendimento a mulheres vítimas de violência doméstica (Mota \& Aguiar, 2020).

\section{Revisão}

Tratou-se de uma revisão integrativa, por meio da identificação, análise e síntese dos resultados de estudos sobre o mesmo assunto. Este tipo de revisão permite a síntese e a análise de pesquisas desenvolvidas e publicadas sobre determinado assunto, tanto pelo método quantitativo, quanto pelo qualitativo, possibilitando a compreensão mais abrangente de determinado fenômeno, capaz de subsidiar a tomada de decisão, baseada em evidências científicas (Sousa et al., 2018).

As etapas desta revisão foram fundamentadas em um protocolo previamente estabelecido, visando manter o rigor científico e metodológico, a saber: 1) elaboração da pergunta de pesquisa; 2) definição dos critérios de inclusão de estudos e seleção da amostra; 3) representação dos estudos selecionados em formato de tabelas, consideração de todas as características em comum (coleta de dados); 4) análise crítica dos estudos incluídos, identificação das diferenças e conflitos; 5) interpretação/discussão dos resultados; 6) apresentação dos resultados com exposição das evidências encontradas.

Para responder à questão norteadora da revisão "Os profissionais de enfermagem estão preparados para atender mulheres vítimas de violência doméstica?”, realizou-se a busca bibliográfica das publicações indexadas nas bases de dados SCIELO, SCIENCE DIRECT e BVS, a partir dos seguintes descritores: atenção primária à saúde, cuidados de enfermagem, enfermagem, maus-tratos conjugais, notificação, protocolos, violência, violência contra a mulher e violência doméstica. A estratégia de busca dos estudos foi realizada por três pesquisadores.

Os critérios de inclusão das publicações foram estudos relevantes baseados em evidências, publicados entre 2015 e 2020, nas línguas portuguesa e inglesa, disponíveis na íntegra. Os critérios de exclusão foram: duplicidade dos artigos, estudos de caso e estudos fora do tema abordado, além do recorte temporal. Após a leitura do material, os dados foram agrupados em categorias.

Os dados dos estudos selecionados para análise foram sintetizados mediante ano de publicação, autor, tipo de estudo, objetivo e considerações do estudo, descritos em sessão dedicada.

\section{Resultados e discussão}

\section{Descrição das Características do Estudo}

Foram encontrados 394 artigos. Destes, 54 (13,70\%) se repetiam nas bases de dados e 310 (78,68\%) não correspondiam à temática, restando 30 artigos, os quais encontram-se ilustrados na figura 1 . 


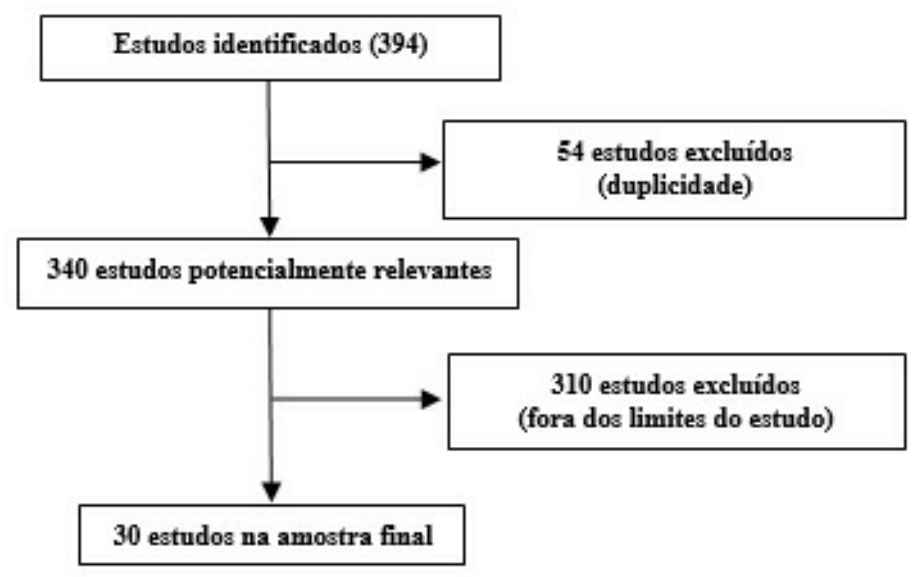

Figura 1. Fluxograma da seleção dos artigos incluídos na revisão integrativa, 2020.

No quadro 1, encontram-se as publicações selecionadas, que demonstram as evidências do despreparo profissional no atendimento às mulheres vítimas de violência doméstica, de acordo com o ano de publicação, autoria, objetivo do estudo, método utilizado e considerações.

\begin{tabular}{|c|c|c|c|c|c|c|}
\hline $\begin{array}{l}\text { Título do } \\
\text { estudo }\end{array}$ & $\begin{array}{l}\text { Autor(e } \\
\text { s) / Ano }\end{array}$ & $\begin{array}{c}\text { Base } \\
\text { de } \\
\text { dados }\end{array}$ & Método & Objetivo & Considerações do estudo & $\begin{array}{c}\text { Evidências do despreparo } \\
\text { das equipes de enfermagem }\end{array}$ \\
\hline $\begin{array}{l}\text { Práticas de } \\
\text { cuidado da } \\
\qquad(0) \\
\text { enfermeira } \\
\text { (o) à mulher } \\
\text { em situação } \\
\text { de violência } \\
\text { conjugal. }\end{array}$ & $\begin{array}{c}\text { Mota et } \\
\text { al., } \\
2020\end{array}$ & Bdenf & $\begin{array}{l}\text { Estudo } \\
\text { descritiv } \\
\text { o } \\
\text { qualitati } \\
\text { vo }\end{array}$ & \begin{tabular}{|} 
Identificar a concepção \\
de cuidado com a \\
mulher em situação de \\
violência conjugal para \\
as (os) enfermeiras da \\
ESF e descrever o \\
cuidado desenvolvidos \\
em relação à mulher em \\
situação de violência \\
conjugal pelo(a) \\
enfermeiro(a). \\
\end{tabular} & $\begin{array}{l}\text { As mulheres em situação de violência } \\
\text { apresentam dificuldade para reconhecer } \\
\text { as situações que envolvem a violência } \\
\text { conjugal, descaracterizando o fato como } \\
\text { grave problema de saúde pública. } \\
\text { Destacou-se como facilidade o rápido } \\
\text { vínculo que a equipe consegue } \\
\text { estabelecer com a paciente. }\end{array}$ & $\begin{array}{l}\text { - Falta de preparo dos } \\
\text { enfermeiros. }\end{array}$ \\
\hline $\begin{array}{l}\text { Violência } \\
\text { contra } \\
\text { mulher: } \\
\text { Acolhimento } \\
\text { na estratégia } \\
\text { saúde da } \\
\text { família }\end{array}$ & $\begin{array}{l}\text { Martins } \\
\text { et al., } \\
2016\end{array}$ & Bdenf & $\begin{array}{c}\text { Estudo } \\
\text { descritiv } \\
\text { o } \\
\text { qualitati } \\
\text { vo }\end{array}$ & $\begin{array}{c}\text { Analisar quatro esferas } \\
\text { no acolhimento às } \\
\text { mulheres na ESF, } \\
\text { voltadas a situações de } \\
\text { violência, sendo elas: } \\
\text { estrutura física, equipe } \\
\text { de saúde, organização } \\
\text { das ações e fluxo de } \\
\text { atendimento. }\end{array}$ & $\begin{array}{l}\text { Os espaços físicos não proporcionam } \\
\text { condições de privacidade, conforto, } \\
\text { segurança e acesso interno facilitado às } \\
\text { mulheres em situação de violência. A } \\
\text { equipe preocupa-se em investigar sinais e } \\
\text { sintomas relacionados a alterações } \\
\text { físicas e biopsicossociais, negligenciando } \\
\text { o assunto de violência, somada à falta de } \\
\text { padronização nos processos e baixa } \\
\text { organização no fluxo de atendimento. }\end{array}$ & 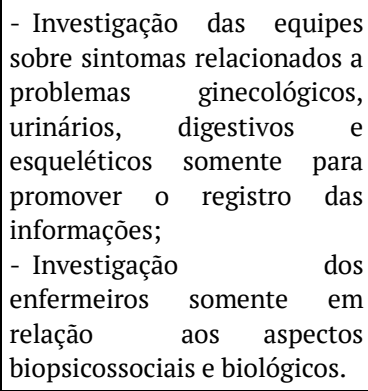 \\
\hline $\begin{array}{l}\text { Percepções } \\
\text { de } \\
\text { enfermeiros } \\
\text { da APS no } \\
\text { atendimento } \\
\text { às mulheres } \\
\text { vítimas de } \\
\text { violência } \\
\text { sexual }\end{array}$ & $\begin{array}{l}\text { Mota \& } \\
\text { Aguiar, } \\
2020\end{array}$ & Lilacs & \begin{tabular}{|} 
Estudo \\
descritiv \\
o \\
explorat \\
ório \\
qualitati \\
vo
\end{tabular} & $\begin{array}{l}\text { Analisar a percepção } \\
\text { dos enfermeiros sobre o } \\
\text { atendimento às } \\
\text { mulheres vítimas de } \\
\text { violência sexual na } \\
\text { atenção primária. }\end{array}$ & $\begin{array}{l}\text { Os profissionais da enfermagem são } \\
\text { despreparados para atender mulheres } \\
\text { que vivenciaram um episódio de violência } \\
\text { sexual, sobretudo pela falta de } \\
\text { conhecimento específico e a dificuldade } \\
\text { na identificação dos casos. }\end{array}$ & $\begin{array}{l}\text { - Falta de conhecimento } \\
\text { acerca da temática; } \\
\text { - Ausência de empatia e a } \\
\text { fragilidade em realizar a } \\
\text { escuta qualificada dos } \\
\text { enfermeiros. }\end{array}$ \\
\hline $\begin{array}{l}\text { Violência } \\
\text { sexual } \\
\text { contra } \\
\text { mulheres: a } \\
\text { prática de } \\
\text { enfermeiros }\end{array}$ & $\begin{array}{c}\text { Baptista } \\
\text { et al., } \\
2015\end{array}$ & Lilacs & \begin{tabular}{|} 
Estudo \\
descritiv \\
o \\
qualitati \\
vo \\
transvers \\
al
\end{tabular} & $\begin{array}{c}\text { Investigar a prática dos } \\
\text { enfermeiros acerca da } \\
\text { violência sexual contra } \\
\text { mulheres. }\end{array}$ & $\begin{array}{l}\text { Geralmente, os profissionais de saúde } \\
\text { não possuem habilidade de comunicação } \\
\text { para conversar e investigar sobre essa } \\
\text { temática, por medo de ofendê-las ou de se } \\
\text { envolverem em assuntos com os quais } \\
\text { não possuem recursos e/ou habilidades } \\
\text { para resolvê-los. }\end{array}$ & $\begin{array}{l}\text { - Ausência de equipamentos } \\
\text { para diagnosticar, tratar e } \\
\text { contribuir para a prevenção da } \\
\text { ocorrência da violência sexual; } \\
\text { - Ausência de protocolos; } \\
\text { - Falta de treinamento e/ou } \\
\text { capacitação para uma } \\
\text { assistência integral no local de } \\
\text { trabalho. }\end{array}$ \\
\hline $\begin{array}{l}\text { Representaç } \\
\text { ões sociais } \\
\text { de } \\
\text { enfermeiras } \\
\text { acerca da }\end{array}$ & $\begin{array}{l}\text { Acosta } \\
\text { et al., } \\
2018\end{array}$ & Scielo & $\begin{array}{c}\text { Estudo } \\
\text { explorat } \\
\text { ório } \\
\text { descritiv } \\
\text { o }\end{array}$ & $\begin{array}{l}\text { Analisar a estrutura e } \\
\text { os conteúdos das } \\
\text { representações sociais } \\
\text { de enfermeiras acerca }\end{array}$ & $\begin{array}{l}\text { A agressão física é visível, portanto, de } \\
\text { fácil identificação pela sociedade e } \\
\text { profissionais, favorecendo a abordagem } \\
\text { do assunto. Na agressão verbal } \\
\text { dificilmente as mulheres procuram ajuda }\end{array}$ & $\begin{array}{l}\text { - Ausência de ferramentas que } \\
\text { privem a inércia profissional } \\
\text { frente ao desconhecido e ao }\end{array}$ \\
\hline
\end{tabular}




\begin{tabular}{|c|c|c|c|c|c|c|}
\hline \begin{tabular}{l|} 
violência \\
doméstica \\
contra a \\
mulher: \\
estudo com \\
abordagem \\
estrutural \\
\end{tabular} & & & $\begin{array}{c}\text { qualitati } \\
\text { vo }\end{array}$ & $\begin{array}{l}\text { da violência doméstica } \\
\text { contra a mulher. }\end{array}$ & $\begin{array}{l}\text { externa, tendendo a aceitar e justificar as } \\
\text { atitudes do agressor. Os elementos } \\
\text { periféricos são caracterizados pelo medo } \\
\text { que a vítima e a equipe sentem em agir } \\
\text { contra o agressor, reconhecendo a } \\
\text { violência como um ato inaceitável. }\end{array}$ & $\begin{array}{|lll|}\begin{array}{l}\text { receio de críticas pelos } \\
\text { colegas. }\end{array} & & \\
\end{array}$ \\
\hline $\begin{array}{c}\text { Atuação dos } \\
\text { enfermeiros } \\
\text { na } \\
\text { identificação } \\
\text { e notificação } \\
\text { dos casos de } \\
\text { violência } \\
\text { contra a } \\
\text { mulher }\end{array}$ & $\begin{array}{l}\text { Freitas } \\
\text { et al., } \\
2017\end{array}$ & Lilacs & $\begin{array}{c}\text { Estudo } \\
\text { qualitati } \\
\text { vo }\end{array}$ & $\begin{array}{c}\text { Compreender a atuação } \\
\text { destes profissionais na } \\
\text { identificação e } \\
\text { notificação dos casos de } \\
\text { violência contra a } \\
\text { mulher nessa } \\
\text { modalidade de } \\
\text { atendimento do SUS }\end{array}$ & $\begin{array}{l}\text { Na assistência às mulheres vítimas de } \\
\text { violência, a agressão psicológica e física } \\
\text { dá-se como uma realidade comum para os } \\
\text { profissionais, que identificam os casos } \\
\text { através da primeira etapa do processo de } \\
\text { enfermagem (histórico). A resistência e o } \\
\text { medo das vítimas em tornar a agressão } \\
\text { registrada em algum espaço público, } \\
\text { expondo a identidade do agressor é o } \\
\text { fator } \\
\text { que mais incomoda os profissionais de } \\
\text { saúde. }\end{array}$ & $\begin{array}{l}\text { - Descontinuidade entre } \\
\text { assistência e notificação, } \\
\text { interpretado por muitos como } \\
\text { um serviço burocrático e } \\
\text { muitas vezes, designado para } \\
\text { outro profissional e não para o } \\
\text { enfermeiro. } \\
- \text { O caráter subjetivo do } \\
\text { profissional; } \\
\text { - Receio de envolvimento com } \\
\text { a história da vítima. }\end{array}$ \\
\hline $\begin{array}{l}\text { Representaç } \\
\text { ão da } \\
\text { violência } \\
\text { doméstica } \\
\text { contra a } \\
\text { mulher: } \\
\text { comparação } \\
\text { entre } \\
\text { discentes de } \\
\text { enfermagem }\end{array}$ & \begin{tabular}{|c|} 
Silva et \\
al., 2018
\end{tabular} & Scielo & $\begin{array}{c}\text { Estudo } \\
\text { qualitati } \\
\text { vo }\end{array}$ & \begin{tabular}{|c|} 
Identificar e comparar a \\
estrutura e conteúdo \\
das representações da \\
violência doméstica \\
contra a mulher entre \\
discentes das séries \\
iniciais e finais de um \\
curso de graduação em \\
Enfermagem
\end{tabular} & $\begin{array}{l}\text { As discentes citaram diversos tipos de } \\
\text { expressões, dentre elas repúdio, raiva e } \\
\text { tristeza, crime, machismo, submissão e } \\
\text { dependência financeira, tentando definir } \\
\text { seus sentimentos ao presenciar casos de } \\
\text { violência doméstica contra a mulher. } \\
\text { Verificaram que algumas enfermeiras } \\
\text { procuram não se envolver com a situação } \\
\text { de violência contra a mulher, acreditando } \\
\text { que é um trabalho para o profissional } \\
\text { especialista. }\end{array}$ & $\begin{array}{l}\text { - Medo das represálias do } \\
\text { agressor; } \\
\text { - Desconhecimento sobre suas } \\
\text { atribuições frente aos casos e } \\
\text { constatação da ausência de } \\
\text { estratégias de ação. }\end{array}$ \\
\hline $\begin{array}{l}\text { Aspectos } \\
\text { éticos e } \\
\text { legais no } \\
\text { cuidado de } \\
\text { enfermagem } \\
\text { às vítimas de } \\
\text { violência } \\
\text { doméstica }\end{array}$ & $\begin{array}{l}\text { Acosta } \\
\text { et al., } \\
2017\end{array}$ & Scielo & $\begin{array}{c}\text { Estudo } \\
\text { qualitati } \\
\text { vo }\end{array}$ & $\begin{array}{c}\text { Analisar o } \\
\text { conhecimento de } \\
\text { enfermeiras } \\
\text { hospitalares sobre os } \\
\text { aspectos éticos e legais } \\
\text { no cuidado de } \\
\text { enfermagem às vítimas } \\
\text { de violência doméstica }\end{array}$ & $\begin{array}{l}\text { O estudo permitiu identificar lacunas no } \\
\text { conhecimento das enfermeiras acerca dos } \\
\text { aspectos éticos e legais em relação ao } \\
\text { cuidado de mulheres vítimas de violência } \\
\text { doméstica. }\end{array}$ & $\begin{array}{l}\text { - Desconhecimento sobre a } \\
\text { notificação compulsória } \\
\text { - Dificuldade dos profissionais } \\
\text { da saúde na abordagem da } \\
\text { vítima, identificação dos } \\
\text { casos, adoção de condutas } \\
\text { adequadas e encaminhamento } \\
\text { das vítimas aos serviços de } \\
\text { apoio. }\end{array}$ \\
\hline $\begin{array}{l}\text { Compreende } \\
\text { ndo a } \\
\text { violência } \\
\text { conjugal: um } \\
\text { estudo em } \\
\text { Grounded } \\
\text { Theory }\end{array}$ & $\begin{array}{c}\text { Carneiro } \\
\text { et al., } \\
2019\end{array}$ & Scielo & $\begin{array}{c}\text { Estudo } \\
\text { qualitati } \\
\text { vo }\end{array}$ & \begin{tabular}{|} 
Compreender o \\
fenômeno da violência \\
conjugal a partir da \\
experiência de \\
mulheres em processo \\
judicial e de \\
profissionais da rede de \\
atenção a mulheres em \\
situação de violência
\end{tabular} & $\begin{array}{l}\text { No que tange aos ambientes da saúde, } \\
\text { percebe-se a necessidade de maior } \\
\text { aproximação entre os profissionais da } \\
\text { saúde e a temática da violência, em } \\
\text { especial dos profissionais de } \\
\text { enfermagem, devido a sua proximidade } \\
\text { com a comunidade e sua atuação na } \\
\text { gestão do cuidado na ESF. Na APS, podem } \\
\text { viabilizar o cuidado a mulheres e crianças } \\
\text { em situação de violência, direcionando- } \\
\text { as aos diferentes lugares da rede de } \\
\text { atenção, oferecendo espaços de } \\
\text { empoderamento feminino na perspectiva } \\
\text { de grupos reflexivos. }\end{array}$ & $\begin{array}{l}\text { - Ausência de qualificação da } \\
\text { equipe de enfermagem, com } \\
\text { base em uma formação } \\
\text { curricular abrangente na } \\
\text { temática, favorecendo o } \\
\text { reconhecimento dos casos, } \\
\text { acolhimento ro ra } \\
\text { acompanhamento da mulher } \\
\text { durante e após o processo de } \\
\text { decisão para ruptura do ciclo } \\
\text { violento. }\end{array}$ \\
\hline $\begin{array}{l}\text { Atenção à } \\
\text { saúde das } \\
\text { mulheres em } \\
\text { situação de } \\
\text { violência: } \\
\text { desarticulaçã } \\
\text { o dos } \\
\text { profissionais } \\
\text { da rede } \\
\end{array}$ & $\begin{array}{l}\text { Arboit et } \\
\text { al., } 2017\end{array}$ & Scielo & $\begin{array}{c}\text { Estudo } \\
\text { descritivo } \\
\text { qualitativ } \\
\text { o } \\
\text { exploratór } \\
\text { io }\end{array}$ & \begin{tabular}{|} 
Conhecer as \\
concepções e ações de \\
profissionais de saúde \\
sobre a rede de atenção \\
às mulheres em \\
situação de violência
\end{tabular} & $\begin{array}{l}\text { Os profissionais de saúde reconhecem a } \\
\text { importância da rede de atenção à saúde } \\
\text { no enfrentamento da problemática da } \\
\text { violência contra as mulheres, no entanto, } \\
\text { suas concepções e ações são limitadas } \\
\text { pela desarticulação ou ausência de } \\
\text { integração entre os profissionais e } \\
\text { serviços da rede de atenção. }\end{array}$ & 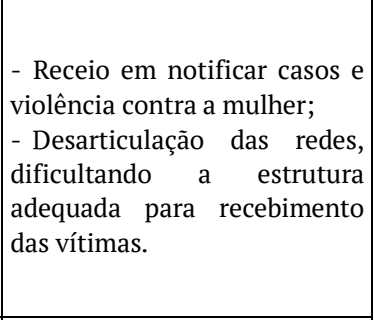 \\
\hline $\begin{array}{c}\text { Violência } \\
\text { contra as } \\
\text { mulheres na } \\
\text { prática de } \\
\text { enfermeiras } \\
\text { da atenção } \\
\text { primária à } \\
\text { saúde }\end{array}$ & $\begin{array}{c}\text { Silva \& } \\
\text { Ribeiro, } \\
2020\end{array}$ & Scielo & \begin{tabular}{|} 
Estudo \\
descritiv \\
o \\
qualitati \\
vo
\end{tabular} & $\begin{array}{c}\text { Compreender como os } \\
\text { enfermeiros que atuam } \\
\text { na APS identificam a } \\
\text { violência contra as } \\
\text { mulheres e descrever a } \\
\text { assistência de } \\
\text { enfermagem prestada a } \\
\text { essas mulheres }\end{array}$ & $\begin{array}{l}\text { Os enfermeiros percebem a violência } \\
\text { contra as mulheres e compreendem seus } \\
\text { diversos tipos, contudo ainda enfrentam } \\
\text { dificuldade ao prestar assistência à vítima } \\
\text { de forma interdisciplinar e intersetorial, } \\
\text { passando pela educação em saúde, } \\
\text { preparando os profissionais que estão sob } \\
\text { sua responsabilidade para este } \\
\text { atendimento. }\end{array}$ & $\begin{array}{lr}\text { - Incapacidade } & \text { dos } \\
\text { profissionais para } & \text { o } \\
\text { reconhecimento de situações } \\
\text { que envolvem violência. }\end{array}$ \\
\hline
\end{tabular}




\begin{tabular}{|c|c|c|c|c|c|c|}
\hline $\begin{array}{l}\text { Rota crítica } \\
\text { de mulheres } \\
\text { em situação } \\
\text { de violência } \\
\text { por parceiro } \\
\text { íntimo }\end{array}$ & $\begin{array}{c}\text { Baragatt } \\
\text { i et al., } \\
2018\end{array}$ & Scielo & \begin{tabular}{|c|} 
Estudo \\
qualitati \\
vo
\end{tabular} & $\begin{array}{c}\text { Conhecer e analisar a } \\
\text { rota crítica de mulheres } \\
\text { em situação de } \\
\text { violência, na } \\
\text { perspectiva delas, } \\
\text { perpetrada por parceiro } \\
\text { íntimo até um Centro } \\
\text { de Referência de um } \\
\text { município brasileiro }\end{array}$ & $\begin{array}{l}\text { Os fatores motivadores para as mulheres } \\
\text { buscarem ajuda foram o aumento da } \\
\text { gravidade das agressões, o impacto da } \\
\text { violência nos filhos e o apoio familiar. }\end{array}$ & $\begin{array}{l}\text { - Dificuldades de alguns } \\
\text { profissionais em identificar a } \\
\text { violência como causa } \\
\text { associada à busca pelo serviço } \\
\text { de saúde; } \\
\text { - Despreparo de alguns } \\
\text { profissionais para o } \\
\text { encaminhamento dos casos. }\end{array}$ \\
\hline $\begin{array}{c}\text { Estudo } \\
\text { transversal } \\
\text { de instrução } \\
\text { de violência } \\
\text { doméstica } \\
\text { em } \\
\text { enfermagem } \\
\text { e programas } \\
\text { de parteira: } \\
\text { fora de } \\
\text { sintonia com } \\
\text { as } \\
\text { expectativas } \\
\text { da } \\
\text { comunidade }\end{array}$ & $\begin{array}{c}\text { Hutchin } \\
\text { so et al., } \\
2020\end{array}$ & $\begin{array}{c}\text { Scienc } \\
\text { e direct }\end{array}$ & $\begin{array}{l}\text { Estudo } \\
\text { qualitati } \\
\text { vo } \\
\text { transvers } \\
\text { al }\end{array}$ & $\begin{array}{l}\text { Examinar a percepção } \\
\text { auto relatada dos } \\
\text { estudantes de } \\
\text { graduação sobre o } \\
\text { conteúdo da violência } \\
\text { doméstica em seus } \\
\text { programas de estudo, } \\
\text { além de atitudes e } \\
\text { crenças estudantis } \\
\text { sobre violência } \\
\text { doméstica }\end{array}$ & $\begin{array}{l}\text { Mais da metade dos estudantes } \\
\text { pesquisados relataram que a violência } \\
\text { doméstica não foi abordada em seu } \\
\text { programa de estudo. Verificou-se } \\
\text { correlação direta entre a prontidão } \\
\text { percebida pelos alunos para avaliar e } \\
\text { responder à violência doméstica e a } \\
\text { quantidade de conteúdo ensinado em seu } \\
\text { programa de estudo }\end{array}$ & $\begin{array}{l}\text { - Falta de preparo das escolas } \\
\text { de enfermagem quando se } \\
\text { trata de violência doméstica; } \\
\text { - Escassez de informação e } \\
\text { relatos de alunos de } \\
\text { enfermagem que se dizem } \\
\text { despreparados para atuarem } \\
\text { frente à situação. }\end{array}$ \\
\hline $\begin{array}{l}\text { Awareness } \\
\text { and } \\
\text { Attitudes } \\
\text { Towards } \\
\text { Violence and } \\
\text { Abuse } \\
\text { among } \\
\text { Emergency } \\
\text { Nurses }\end{array}$ & $\begin{array}{l}\text { Cho et } \\
\text { al., } \\
2015\end{array}$ & $\begin{array}{c}\text { Scienc } \\
\text { e direct }\end{array}$ & $\begin{array}{l}\text { Estudo } \\
\text { descritiv } \\
\text { o } \\
\text { qualitati } \\
\text { vo }\end{array}$ & $\begin{array}{c}\text { Identificar o grau de } \\
\text { conscientização e } \\
\text { conhecimento jurídico } \\
\text { sobre abuso e violência } \\
\text { em geral e investigar } \\
\text { atitudes relacionadas à } \\
\text { violência doméstica em } \\
\text { enfermeiros de } \\
\text { emergência }\end{array}$ & $\begin{array}{l}\text { O estudo revelou que } 60,0 \% \text { dos } \\
\text { participantes aproximadamente, } \\
\text { experimentaram incidentes de suspeita } \\
\text { de abuso ou violência, no entanto, as } \\
\text { taxas de notificação foram baixas. A } \\
\text { maioria dos enfermeiros sabia que devia } \\
\text { realizar a denúncia da violência. Destes, } \\
\text { quase a metade não sabia se teria a } \\
\text { responsabilidade legal para a realização } \\
\text { da denúncia. A maioria compreendeu que } \\
\text { mesmo que a violência doméstica seja } \\
\text { grave, não deve ser sugerido às vítimas } \\
\text { que fujam, deixando as crianças em casa, } \\
\text { identificando no agressor o sujeito que } \\
\text { carece de tratamento. }\end{array}$ & $\begin{array}{l}\text { - Conhecimento insuficiente } \\
\text { para lidar com a situação da } \\
\text { violência; } \\
\text { - Experiência educacional } \\
\text { limitada em questão de } \\
\text { violência e abuso. }\end{array}$ \\
\hline
\end{tabular}

Quadro 1. Integração das referências que evidenciam o despreparo das equipes de enfermagem no atendimento às vítimas de violência doméstica. Fonte de autoria. Brasil, São Paulo, 2020.

A integração da literatura selecionada permite inferir que a falta de qualificação para identificar os casos de violência, bem como conhecimento insuficiente sobre o tema e sobre suas ações mediante está problemática são as principais evidências do despreparo das equipes de enfermagem para uma assistência adequada à mulher, vítima de violência doméstica.

A violência de gênero não representa um novo fenômeno na sociedade, sendo tão antiga quanto a humanidade. Embora a conquista da mulher represente um grande avanço para a sociedade, a violência insiste em caracterizar-se como um dos mais graves problemas enfrentados pelas mulheres (Durães et al., 2020).

A OMS estipula a violência como o uso intencional da força ou do poder, real ou em ameaça, contra si próprio, contra outra pessoa, um grupo ou uma comunidade, que resulte ou tenha a possibilidade de resultar em lesão, morte, dano psicológico e/ou privação (Polidoro et al., 2020).

Desta forma, pode-se definir violência doméstica ou intrafamiliar qualquer ato, conduta ou omissão que sirva para infligir sofrimentos físicos, sexuais, mentais ou econômicos, de modo direto ou indireto a qualquer pessoa que habite no mesmo ambiente doméstico que o agressor, seja cônjuge, esposo, ex-cônjuge, ex-marido ou qualquer pessoa que compartilhe o mesmo teto, colocando em risco a segurança que um lar precisa oferecer (Miranda, 2019).

A violência é um problema que se faz presente e frequente em todas as fases da história. Ao longo dos anos foi se tornando algo subsistente em nosso cotidiano, e é tratada como pouco comovente. Em 1998, a OMS publicou que a VCM no âmbito doméstico estava sendo evidenciada e documentada com maior frequência em comparação aos anos anteriores em todos os países e pouco foi feito para mudar o quadro. A frase que muito se diz "ou é minha ou não é de ninguém" indica algo que atualmente foi normatizado por parte significativa da população, mas, ainda está incorporada na mentalidade de grande parte da humanidade. Um fruto das desigualdades econômicas é acreditar que a violência é um problema distante e não faz parte das 
preocupações de pessoas próximas. A ideia que apenas pessoas em situações precárias são vítimas é um engano, visto que qualquer mulher está vulnerável a vivenciar este fenômeno (Teles \& Melo, 2017).

No âmbito da saúde, a violência praticada pelo parceiro íntimo da vítima classifica-se em quatro modalidades: abuso físico, que ocorre quando alguém causa ou tenta causar dano, com uso da força física intencional, podendo ser manifestada como um ato moderado ou severo, permitindo esse último a inclusão do uso de arma branca ou arma de fogo; abuso psicológico, caracterizado por toda ação ou omissão que cause danos à autoestima da vítima, expresso por agressões verbais ou gestuais que têm como intuito humilhar ou aterrorizar a vítima; abuso sexual, reconhecido como a estimulação e práticas sexuais sem a concordância da vítima, incluindo a obrigação em ter relações impostas por meio de aliciamento, ameaças, agressões físicas ou emocionais. A negligência ou abandono também constitui um tipo de violência, caracterizada pela omissão de atenção e cuidados a alguém que precisa receber (Coelho et al., 2018).

Neste contexto, a violência sexual deve ser considerada como toda ação que seja usada a força física, repressão ou intimidação psicológica com o intuito de realizar atos sexuais sem a consideração do desejo da mulher ou mesmo a exposição da mulher a interações sexuais que propiciem sua vitimização; situação em que o agressor tem como intuito a estimulação da vítima para obter satisfação sexual, envolvendo também a exploração sexual que visa o lucro. O estupro, nessa conjuntura, corresponde a todo ato de cópula anal, oral ou vaginal com o envolvimento peniano ou de objetos à força ou sob ameaça, sujeitando a vítima ao uso de entorpecentes (Barcellos, 2020).

A violência física, por sua vez, traduz qualquer conduta que infrinja a dignidade ou saúde física da mulher, frequentemente expressa por maus tratos e agressão corporal. Na maioria dos casos, o agressor é o parceiro íntimo ou familiar próximo, o que torna a prática comum e disfarçada para pessoas de fora da relação (Vilar \& Costa, 2018).

A violência psicológica ou moral progride de forma silenciosa, nem sempre identificada pela vítima, que ao invés disso, muitas vezes cria artefatos em sua cabeça para aceitar e justificar as ações do agressor, acreditando que o parceiro irá melhorar. Abrange a forma de ofensa verbal repetida, chantagem emocional, privação de bens materiais, financeiros e pessoais, agressão emocional que abala a autoestima da vítima e diversos tipos de ameaças, expressa por meio de olhares, gestos e palavras (Albuquerque, 2019).

Estudos revelam que a subnotificação da violência contra a mulher constitui um fator que cria obstáculos para desvelar a realidade do levantamento dos números de casos, evidenciando a rejeição das mulheres na utilização dos meios legais para sua defesa contra o agressor e, quando o fazem, desistem da denúncia. Para muitas, a violência cotidiana nem mesmo é percebida como violação dos seus direitos, sendo, dessa forma, naturalizada no contexto familiar (Durães et al., 2020).

A violência psicológica é negligenciada pela sociedade por não gerar marcas físicas, alguns artigos não a citam. Esse tipo de violência não atinge somente a vítima, mas também os filhos que presenciaram a situação, podendo reproduzi-la com amigos, familiares e futuramente com a namorada ou parceira de vida (Albuquerque, 2019).

A violência patrimonial ou institucional é caracterizada por qualquer conduta que retém, subtrai, destrói de forma parcial ou total seus objetos, instrumentos de trabalho, documentos pessoais, bens, valores e direitos ou recursos econômicos. Recebe o mesmo tratamento penal que os crimes de furto e roubo, devido à sua gravidade e a reprovação de sua prática pela legislação (Alves, 2019).

Um estudo realizado com o intuito de levantar as produções científicas publicadas na BVS apontou que as principais formas de violência documentadas em 39 manuscritos analisados foram: a física (12,8\%), a sexual e a psicológica (26,3\%), seguida da física e psicológica (14,9\%), resultando no agravo à saúde física e mental como principal consequência dos danos às vítimas (Silva \& Oliveira, 2015).

Os desdobramentos da violência na saúde física da mulher são profundos e decorrentes das agressões sofridas, tais como: hematomas, escoriações, luxações e lacerações, dores pelo corpo, obesidade, síndrome do pânico, crises de gastrite e úlcera, mutilações, fraturas, dificuldades ligadas à sexualidade e complicações obstétricas. A violência também propicia uma maior vulnerabilidade aos acidentes e ao hábito de fumar, favorecendo o uso abusivo de medicamentos, especialmente o de antibióticos e anti-inflamatórios (Bezerra et al., 2019).

Além das consequências físicas, as agressões geram na mulher um sofrimento psicológico a curto e a longo prazo, culminado em sentimentos de aniquilação, tristeza, desânimo, solidão, estresse, baixa autoestima, incapacidade, impotência, ódio e inutilidade (Cidreira, 2017).

Diante da complexidade que abrange o fenômeno da violência, a assistência de enfermagem demanda planejamento para a promoção de um acolhimento confiável, respeitoso e satisfatório, capaz de oferecer à 
vítima as opções de enfrentamento, permitindo-lhes fazer escolhas e fortalecer sua autoestima, oferecendo apoio à vítima no desejo manifesto da realização do registro policial do fato; realizando encaminhamentos a outros órgãos competentes quando necessário e, incentivando a construção de vínculo com as redes de assistência, proteção e de apoio (Durães et al., 2020).

\section{Conclusão}

Este estudo possibilitou concluir que os profissionais de enfermagem necessitam de um melhor preparo e motivação para lidar com a problemática da violência doméstica nos âmbitos psicológico e técnico-científico.

O grande aumento de casos de violência no Brasil emerge a necessidade de profissionais que superem o medo do envolvimento no caso, a fim de que o tratamento não seja prejudicado, na medida em que a vítima não se sente acolhida, resultando, consequentemente, na redução das taxas de notificação. É importante ressaltar que a falta de preparo durante a formação desses profissionais, decorrente da ausência de investimento nesse tipo de temática, impossibilita que eles sejam bem-sucedidos ao enfrentar essas situações. Sendo assim, é necessário buscar atualizações e aperfeiçoamento para uma assistência adequada à mulher frente a esta vulnerabilidade.

A violência doméstica causa danos não só à mulher, mas também a todos os indivíduos pertencentes ao ambiente intrafamiliar, trazendo desdobramentos a curto, médio e longo prazo. Dessa forma, faz-se necessária a conscientização dessa realidade para que haja um acolhimento digno, respeitoso e resolutivo a cada mulher, proporcionando assim, uma assistência qualificada e eficaz.

\section{Referências}

Acosta, D. F., Gomes, V. L. O., Oliveira, D. C., Gomes, G. C., \& Fonseca, A. D. 2017. Aspectos éticos e legais no cuidado de enfermagem às vítimas de violência doméstica. Texto Contexto Enfermagem, 26(3), e6770015.

Acosta, D. F., Gomes, V. L. O., Oliveira, D. C., Marques, S. C., \& Fonseca, A. D. 2018. Representações sociais de enfermeiras acerca da violência doméstica contra a mulher: estudo com abordagem estrutural. Revista Gaúcha de Enfermagem, 39, e61308.

Albuquerque, N. F. 2019. Violência doméstica e familiar: o impacto na relação com a Lei Maria da Penha. Disponível em: https://www.direitonet.com.br/artigos/

Alves, M. C. S. 2019. Violência patrimonial contra a mulher na constância de relações socioafetivas. Monografia. Ceres, GO: Centro Universitário de Anápolis.

Arboit, J., Padoin, S. M. M., Vieira, L. B., Paula, C. C., Costa, M. C., \& Cortes, L. F. 2017. Atenção à saúde de mulheres em situação de violência: desarticulação dos profissionais em rede. Revista da Escola de Enfermagem da USP, 51, e03207.

Baptista, R. S., Chaves, O. B. B. M., França, I. S. X., Sousa, F. S., Oliveira, M. G., \& Leite, C. C. S. 2015. Violência sexual contra mulheres: a prática de enfermeiros. Revista Rene, 16(2), 210-7.

Baragatti, D. Y., Carlos, D. M., Leitão, M. N. C., Ferriani, M. G. C., \& Silva, E. M. 2018. Rota crítica de mulheres em situação de violência por parceiro íntimo. Revista Latino-Americana de Enfermagem, 26, e3025.

Barcellos, M. 2020. Cartilha de proteção a mulher: ações para o enfrentamento a violência doméstica e familiar. Belém, PA: Ministério público do estado do Pará.

Bezerra, M. B., Paulo, A. P. D. S., Medeiros, H. R. L., \& Rodrigues, E. S. R. C. 2019. Violência de gênero e suas consequências na saúde da mulher. Temas em Saúde, 19(5).

Carneiro, J. B., Gomes, N. P., Campos, L. M., Silva, A. F., Cunha, K. S., \& Costa, D. M. S. C. 2019. Compreendendo a violência conjugal: um estudo em Grounded Theory. Revista Latino-Americana de Enfermagem, 27, e3185.

Cho, O. H., Cha, K. S., \& Yoo, Y. S. 2015. Conscientização e atitudes em relação à violência e ao abuso entre enfermeiros de emergência. Asian Nursing Research, 9(3), 213-8.

Cidreira, M. C. C. B. 2017. Cicatrizes da dor: as consequências da violência doméstica na saúde física da mulher. VIII Jornada Internacional de Políticas Públicas, Universidade Federal do Maranhão,.

Coelho, E. B. S., Silva, A. C. L. G., \& Lindner, S. R. 2018. Violência por parceiro íntimo: definições e tipologias. Florianópolis, SC: Universidade Federal Santa Catarina. 
Durães, B. A., Camacho, B. S., Gomes, J. M. S., Silva, M. K., Oliveira, G. P., Maia, J. S., Santos, M. N., \& Maia, L. F. S. 2020. A mulher contemporânea e a violência: o desafio do rompimento do silêncio. Revista Científica de Enfermagem, 10(30), 54-61.

Freitas, R. J., Sousa, V. B., Costa, T. S., Feitosa, R. M., Monteiro, A. R., \& Moura, N. A. 2017. Atuação dos enfermeiros na identificação e notificação dos casos de violência contra a mulher. HU Revista, 43(2), 91-7.

Hutchinson, M., Doran, F., Brown, J., Douglas, T., East, L., Irwin, P., ... Yates, K. 2020. Um estudo transversal sobre o ensino da violência doméstica em programas de enfermagem e obstetrícia: descompassado com as expectativas da comunidade e dos alunos. Enfermeira Educação Hoje, 84, 104209.

Martins, L. C. A., Silva, E. B., Costa, M. C., Colomé, I. C. S., Fontana, D. G. R., \& Jahn, A. C. 2016. Violência contra mulher: acolhimento na estratégia saúde da família. Cienc Cuid Saude, 15(3), 507-14.

Miranda, J. E. F. 2019. O vigor e aplicação da lei 11.340/06 - Lei Maria da Penha - um enfoque especial na sua aplicação em Porto Velho-RO.

Mota, A. R., Machado, J. C., Santos, N. A., Simões, A. V., Pires, V. M. M. M., \& Rodrigues, V. P. 2020. Práticas de cuidado da (o) enfermeira (o) à mulher em situação de violência conjugal. Revista Online de Pesquisa, $12,840-9$.

Mota, J. A., \& Aguiar, R. S. 2020. Percepções de enfermeiros da atenção primária no atendimento às mulheres vítimas de violência sexual. Revista Nursing, 23(262), 3648-51.

Noleto, K. C., \& Barbosa, I. A. 2019. A efetividade da Lei Maria da Penha no enfrentamento a violência doméstica e familiar contra a mulher. Disponível em: https://ambitojuridico.com.br/

Polidora, M., Cunda, B. V., \& Canavese, D. 2020. Vigilância da violência no Rio Grande do Sul: panorama da qualidade e da quantidade das informações no Sistema de Informação de Agravos de Notificação (SINAN) de 2014 a 2018. Saúde em Redes, 6(2), 195-206.

Senado Federal. 2013. Violência Doméstica e Familiar Contra a Mulher. DataSenado: Secretaria de Transparência.

Silva, C. D., Gomes, V. L. O., Fonseca, A. D., Gomes, M. T., \& Arejano, C. B. 2018. Representação da violência doméstica contra a mulher: comparação entre discentes de enfermagem. Revista Gaúcha de Enfermagem, 39, e63935.

Silva, L. E. L., \& Oliveira, M. L. C. O. 2015. Violência contra a mulher: revisão sistemática da produção científica nacional no período de 2009 a 2013. Ciência \& Saúde Coletiva, 20(11), 3523-32.

Silva, V. G., \& Ribeiro, P. M. 2020. Violência contra as mulheres na prática de enfermeiras da atenção primária à saúde. Escola Anna Nery, 24(4), e20190371.

Sousa, L. M. M., Firmino, C.F., Marques-Vieira, C. M. A., Severino, S. S. P., \& Pestana, H. C. F. C. 2018. Revisões da literatura científica: tipos, métodos e aplicações em enfermagem. Revista Portuguesa de Enfermagem de Reabilitação, 1(1), 45-55.

Teles, M. A. A., \&; Melo, M. 2017. O que é violência contra a mulher. São Paulo, SP: Coleção Primeiros Passos.

Vilar, A. T. S., \& Costa., T. G. 2018. Uma visão dos aspectos psicossociais na saúde da mulher vítima de violência. III Jornada Acadêmica do Hupaa.

Waiselfisz, J. J. 2015. Mapa da Violência 2015: Homicídio de mulheres no Brasil. Brasília, DF: Flacso Brasil.

\section{Minicurrículo}

Anna Beatriz Brito Domingues. Graduação acadêmica de enfermagem.

Erica Cristina da Silva. Graduação acadêmica de enfermagem.

Helena Ferreira Santos Bispo. Graduação acadêmica de enfermagem. 
Janize Silva Maia. Enfermeira obstetra, doutora em Ciências da Saúde, mestre em Educação. Docente do curso de Enfermagem da Universidade Anhembi Morumbi - UAM. São Paulo (SP), Brasil.

Como citar: Domingues, A.B.B., Silva, E.C., Bispo, H.F.S., \& Maia, J.S. Violência doméstica: mulheres vítimas da violência e do despreparo das equipes de enfermagem. Pubsaúde, 5, 107. DOI: https://dx.doi.org/10.31533/pubsaude5.a107

Recebido: 5 dez. 2020.

Revisado e aceito: 16 dez. 2021.

Conflito de interesse: os autores declaram, em relação aos produtos e companhias descritos nesse artigo, não ter interesses associativos, comerciais, de propriedade ou financeiros que representem conflito de interesse.

Licenciamento: Este artigo é publicado na modalidade Acesso Aberto sob a licença Creative Commons Atribuição 4.0 (CC-BY 4.0). 